\title{
INCIDENCE OF OPEN NEURAL TUBE DEFECT (ONTD)
}

Incidence of Open Neural Tube Defect in Asir Province, Southern region of Saudi Arabia

Dr. Algahtany Mubarak Ali

ABSTRACT... Objective: To determine the incidence of open neural tube defect (ONTD) in Asir Province, Southern region of KSA and compare with eastern region and central region of the country and determine if the incidence is stable or changing over the years. Design: Prospective study. Period: January 2009 to December 2011 and retrospective study of the period March 2003 to January 2007 . Material and methods: We compared the number of newborns with ONTD for different periods. Results: Out of 18 patients in the prospective group 12 were female and 6 male. The incidence is 1.34 per 1000 live births. Hospital Data from year 2003 to 2007 shows 32 total admissions for ONTD in 4 years. Conclusions: Comparison with eastern region and central regions gives a slightly high incidence comparing 1.34/1000 live births to 1.09/1000 in central region and $0.97 / 1000$ live births in eastern region. There is a decline in the number of ONTD cases in Asir Province, Southern region of Saudi Arabia.

Key words: Neural tube, Defect, Asir, Saudi Arabia

Article Citation

Ali AM. Incidence of open neural tube defect (ONTD); Incidence of open neural tube defect in Asir Province, Southern region of Saudi Arabia. Professional Med J 2013;20(2): 199-201.

\section{INTRODUCTION}

Open neural tube defects (ONTDs) are important group of birth defects. Their incidence differs from one country to another due to different factors. Many studies have reported a declining frequency of ONTD at birth ${ }^{1}$. The decline has been strongest in areas with a high previous prevalence of ONTD. There are probably different reasons for this decline, one of them is elective abortion after prenatal diagnosis. However, before the introduction of prenatal diagnosis, a decline in ONTD rate was noted in many countries including Sweden, apparently not due to under- reporting ${ }^{2}$. The efficiency of ultrasound screening in the prenatal diagnosis of ONTD has been demonstrated but most of these studies are either hospital-based or multicentre studies. There are few population-based studies of this problem $^{3}$. In recent years, a further cause of the decline in ONTD rate has been suggested: the use of periconceptional folic acid supplementation and/or food fortification with folic acid ${ }^{4}$.

Newborns with ONTD were identified from various health registers. The main source was the Medical Birth Registry from which infants with ONTD were identified from ICD (International Classification of Diseases) codes, given at the paediatric examination of the newborn ${ }^{5}$. Although all births have to be reported to this register, a small percentage is missed each year. Recording of congenital malformations is incomplete in this register so data were supplemented from the Register for Congenital Malformations, a surveillance register of major congenital malformations ${ }^{6}$. From 2003 onwards, data from the Hospital Discharge Register were also used and the identification of the infants with ONTD was based on ICD codes.

Prenatal diagnosis of ONTD is based on ultrasound examination since maternal serum AFP screening has not been used other than sporadically. Approximately $97 \%$ of pregnant women attend at least one ultrasound screening during their pregnancy ${ }^{7}$. Most of these screening examinations are performed by specially trained midwives.

\section{OBJECTIVE}

To determine the incidence of open neural tube defect (ONTD) in southern region of KSA and compare with eastern region and central region of the country. And look if the number of cases diagnosed is on the rise or the fall. 


\section{MATERIAL AND METHODS}

This prospective, hospital based study was carried out from January 2009 to December 2011 to estimate the incidence and the male to female ratio of ONTD in Asir Province, Southern region of Saudi Arabia. A total of 18 cases were admitted at Asir Central hospital. All cases of ONTD in Asir region present or get referred immediately after birth to Asir Central hospital which is the only Tertiary care unit with faculty of neurosurgery in the region. The incidence was calculated knowing the number of live births in Asir Province from ministry of health birth registry. Hospital Data from March 2003 to January 2007 were reviewed retrospectively shows 32 total admissions for ONTD in 4 years.

\section{RESULTS}

During the study period it was found that in Asir Province the incidence of ONTD was 1.34 in 1000 live births whereas it was 1.09/1000 live births and 0.97/1000 live births in Central and Eastern region respectively.

Out of 18 cases, 12 (66.7\%) were male and 6 (33.3\%) were female patients as shown in table-l.

\begin{tabular}{|c|c|c|}
\hline Sex & No. of cases & Percentage \\
\hline Male & 12 & 66.7 \\
\hline Female & 06 & 33.3 \\
\hline & Table-I. Sex distribution $(\mathbf{n}=18)$ \\
\end{tabular}

In the retrospective arm of this study the hospital data from year March 2003 to January 2007 shows 32 total admissions for ONTD in 4 years. This indicate decline in the number of cases over the years in Asir Province of the Southern region of Saudi Arabia.

\section{DISCUSSION}

There has been a marked decline in the prevalence at birth of ONTD. This is worldwide trend that was also shown in our study of Asir population. Such a decline is difficult to attribute to specific reason but the contribution of prenatal diagnosis followed by elective abortion is undoubtedly strong in some cultures. Certainly this was not the case in our population. Though prenatal screening and diagnosis of intrauterine congenital malformation is the routine for all pregnant women in Saudi Arabia, elective abortion is not practiced. It is actually not accepted practice in our local community both for social and religious reasons. The only exception to this is when it is determined that the continuation of pregnancy impose a threat to the maternal health. We observed that the efficiency of prenatal diagnosis of ONTD increased during the observation period and estimates made for the rest of the country indicated a similar but weaker trend.

The intracranial signs for ONTD were first reported ${ }^{8}$. These are the 'banana sign' due to Arnold Chiari malformation (displacement of the cerebral vermis) and 'lemon sign' due to frontal bossing. A dilatation of the lateral ventricles is present in up to $70 \%$ of ONTD in the second trimester". These cranial signs have substantially contributed to the better detection rate of ONTD $^{10}$. Maternal serum AFP screening is used in many countries, notably in those with a high incidence of ONTD. The sensitivity of serum screening was estimated to be $84-92 \%{ }^{11}$. Patients with a positive serum screening are usually referred to expert sonography and in these cases the accuracy of diagnosis is close to $100 \%{ }^{12}$. The diagnostic accuracy in routine non-targeted examinations is uncertain ${ }^{9}$. There are several prospective studies on low-risk populations. The RADIUS study in which ultrasound was used in combination with maternal AFP screening reported a sensitivity of $80 \%{ }^{13}$. In other studies, the sensitivity was much lower, $30 \%$ and $40 \%$ when maternal serum screening was presumably not used $^{14,15}$.

Use of folic acid before and during early pregnancy has been thought to reduce the rate of ONTD. Various estimates have been made of the efficiency but use of 
folic acid supplementation is believed to cause a reduction of $50 \%$. No food fortification with folic acid has occurred in Sweden during the observation period but folic acid supplements $(0.4 \mathrm{mg})$ have been available. Folic acid supplement during pregnancy is widely practiced in Saudi Arabia in general and specifically in the local community, the subject of this paper. Therefor it is probably a major cause for the decrease in the number of ONTD in Asir Province. Other possible explanation is public awareness leading to avoidance of conception by mothers with previously affected child and avoidance of close relatives marriage.

\section{Copyright@ 23 Nov, 2012.}

\section{REFERENCES}

1. Elwood JM, Little J, Elwood JH. editors, Epidemiology and control of neural tube defects. Oxford Medical Publications, 1992.

2. Mitchell LE, Adzick NS, Melchionne J, Pasquariello PS, Sutton LN, Whitehead AS. Spina bifida. Lancet 2004 64(9448): 1885-95.

3. Pilu GL, Hobbins JC. Sonography of fetal cerebrospinal anomalies. Prenat Diagn 2002; 22: 321-30.

4. Persad VL, Van den Hof MC, Dube JM. Incidence of open neural tube defects in Nova Scotia after folic acid fortification. CMAJ 2002; 167: 241-5.

5. Cnattingius S, Ericson A, Gunnarskog J. A quality study of a medical birth registry. Scand J Soc Med 1990; 18: 143-8.

6. Juranek, J, Salman MS. Anomalous development of brain structure and function in spina bifida myelomeningocele. Developmental Disabilities. 2010; 16: 23-30.
7. Iwamoto J, Abe H, Tsukimura Y, Wakano K. Relationship between radiographic abnormalities of lumbar spine and incidence of low back pain in high school rugby players: a prospective study. Scandinavian journal of medicine \& science in sports 2005; 15(3).

8. Juranek, J; Salman MS. "Anomalous development of brain structure and function in spina bifida myelomeningocele". Developmental Disabilities. 2010; 16: 23-30.

9. Chiari malformation fact sheet. Nationallnstitute of Neurological disorders and stroke. Ninds.nih.gov. 2011 09-16. Retrieved 2011-10-23.

10. Watson WJ, Cheschier NC, Katz VL. The role of ultrasound in evaluation of patients with elevated maternal serum alpha-fetoprotein: a review (Review). Obstet Gynecol 1991; 78: 123-8.

11. Holmbeck, GN; Devine KA. Psychological and family functioning in spina bifida. Developmental Disabilities Research Reviews 2010; 16 (1): 40-6.

12. Nadel AS, Green JK, Holmes LB. Absence of need for amniocentesis in patients with elevated levels of maternal serum alpha-fetoprotein and normal ultrasonographic examinations. N Engl J Med 1990; 323 : 557-61.

13. Steinberg EL, Luger E, Arbel R, Menachem A, Dekel S. A comparative roentgenographic analysis of the lumbar spine in male army recruits with and without lower back pain. Clinical radiology 2003; 58(12): 985-9.

14. Levi S, Hijazi Y, Schaaps JP. Sensitivity and specificity of routine antenatal screening for congenital anomalies by ultrasound: the Belgian multicentric study. Ultrasound Obstet Gynecol 1991;1:102-10.

15. Levi S, Schaaps JP, De Havay P. End result of routine ultrasound screening for congenital anomalies: the Belgian multicentric study 1984-92. Ultrasound Obstet Gynecol 1995; 5: 366-71.

\section{AUTHOR(S):}

DR. ALGAHTANY MUBARAK ALI

Assistant Professor Neurosurgery

Department of Surgery

King Khalid University ABHA,

Kingdom of Saudi Arabia
Correspondence Address:

Dr. Algahtany Mubarak Ali

Assistant Professor Neurosurgery

Department of Surgery

King Khalid University ABHA, Kingdom of Saudi Arabia mubarak01@hotmail.com 